\title{
The Relationship between Telomerase Activity and Clinicopathological Parameters in Colorectal Cancer: A Meta-Analysis
}

\author{
Xue-Cheng Xie ${ }^{1}$, Lian-Ying $\mathrm{Ge}^{2}$, Hao Lai ${ }^{1}$, Hai Qiu${ }^{1}$, Fan Tang ${ }^{1}$, Yu-Zhou Qin ${ }^{1}$ \\ ${ }^{1}$ Department of Gastrointestinal Surgery, Tumor Hospital of Guangxi Medical University, Nanning, China \\ ${ }^{2}$ Department of Endoscopy Center, Tumor Hospital of Guangxi Medical University, Nanning, China
}

Background: Recently, accumulated research has found that the expression of telomerase activity (TA) was associated with colorectal cancer (CRC) advancement, whereas the TA prognostic effect in CRC patients is still controversial.

Aims: To investigate relationships between TA and CRC clinicopathological parameters.

Study Design: Meta-analysis study.

Methods: We searched published studies in databases, such as EMBASE, the Cochrane Library, PubMed, and Ovid databases (last search updated to October 2014) by meeting specified search criteria. The quality of the included studies was usually evaluated and a metaanalysis was implemented by Stata 12.0 software. We used an odds ratio (OR) with a $95 \%$ confidence interval (CI) to evaluate relationship strengths between TA and CRC clinicopathological parameters.

Results: In total, 11 studies (715 patients) were included to assess the relation between TA and metastasis-related parameters in CRC patients. The results indicate that a senior TA expression was connected with the existence of lymph node metastasis (180 patients; $\mathrm{OR}=2.85,95 \% \mathrm{CI}=1.40-5.81, \mathrm{p}=0.004)$, and tumor site (522 patients; OR=2.93, 95\% CI $=1.29-6.67$, $\mathrm{p}=0.010$ ). However, a senior TA expression was not connected with tumor size (137 patients; $\mathrm{OR}=1.57$, 95\% CI $=0.71-3.47, \mathrm{p}=0.267)$, histological differentiation ( 570 patients; $\mathrm{OR}=1.28,95 \% \mathrm{CI}=0.78-2.09$, $\mathrm{p}=0.332$ ), depth of invasion ( 57 patients; OR=3.76, 95\% CI $=0.61-23.04, \mathrm{p}=0.152)$, distant metastasis $(123$ patients; $\mathrm{OR}=1.76,95 \% \mathrm{CI}=0.54-5.74, \mathrm{p}=0.346)$, and clinical stage of the cancer (543 patients; $\mathrm{OR}=1.59$, 95\% $\mathrm{CI}=0.74-3.38, \mathrm{p}=0.232$ ).

Conclusion: This meta-analysis suggests that a positive TA was correlated with lymph node metastasis progression and tumor site of the CRC but did not correlate with other important clinicopathological parameters. TA can play a useful part in the prognosis and treatment of CRC patients, but further studies are required to confirm this.

Keywords: Colorectal neoplasms, meta-analysis, prognosis, telomerase
Colorectal cancer (CRC) is the third most general neoplasm in humans with the CRC mortality rate accounting for around $9 \%$ of all tumor deaths (1). The 5-year survival rate of the early stages of CRC after surgical resection is around $85 \%$, while this rate is meaningfully decreased $(<50 \%)$ in lymph node metastasis positive CRC patients (2). Therefore, early and more accurate detection of tumorigenesis or progression is critical to enhancing therapeutic strategy and prognosis of patients. Accumulating evidence indicates that cellular immortality plays an important role in tumor biology (3).

The indispensable and key factor for tumor immortalization and tumorigenesis is telomerase, an enzyme that protects DNA sequences on chromosome ends. Telomerase can prevent cellular senescence in somatic cells through synthesizing 
the reduplicative telomeric sequence utilizing its template (4). The telomerase synthetic was composed of human telomerase reverse transcriptase (hTERT), an RNA template for telomeric DNA synthesis (hTR), and telomerase associate protein (TP1) (5). Telomerase activity (TA) is the most common molecular marker because of the detection of human neoplasm and can be observed in approximately $85 \%$ of all cancer cells, including CRC (6), but not in normal somatic cells (7). Research also shows that TA increases with adenoma-carcinoma sequences (8).

Cancer prognosis is dependent on a number of clinicopathological features, such as histological type, depth of invasion (T), lymph node metastasis $(\mathrm{N})$, distant metastasis $(\mathrm{M})$, and Dukes' stage. The correlation between telomerase activity and clinicopathological parameters in CRC has been reported by many authors. Since these researches were performed using small research mammal populations, the outcomes remain controversial. Therefore, we have performed the first metaanalysis in the literature to verify the relationship between TA and clinicopathological parameters, and further aimed to elucidate the prognostic role of TA in CRC.

\section{MATERIALS AND METHODS}

\section{Search strategy}

All analyses were based on previous published studies, thus no ethical approvals or patient consents were required. This meta-analysis was carried out according to the meta-analysis guidelines of the Observational Studies in Epidemiology Group (9). Studies were extracted through searching PubMed, EMBASE, the Cochrane Library, and Ovid databases (last search updated to October 2014). The following search strategy was adopted: "colon cancer OR colon carcinoma OR rectum cancer OR rectum carcinoma OR colorectal cancer OR colorectal carcinoma" AND "telomerase". No language constraints were implemented. To identify any other researches meeting the requirement of this meta-analysis, the reference lists of each extracted article were also checked carefully.

\section{Selection criteria}

The criteria for eligibility of a study to be included in this meta-analysis were: i) The disease in patients of the study was colon cancer or rectal cancer; ii) The study had to detect TA in tumor tissues by using the same or a similar method to that used in other selected studies; iii) The study had to investigate the correlation between TA and clinical variables; and iv) The study had to provide sufficient data comparing the TA expression with clinicopathological data that enabled us to calculate the odds ratio (OR). Articles were excluded from this study if i) the study was a review article, letter, or case report; ii) the study was an experiment using cell cultures or animals; iii) the study detected TA from body fluids, stool, or blood; iv) the study lacked key information needed to create $2 \times 2$ tables that correlated TA (positive or negative) with clinicopathological parameters; and v) the study detected hTERT expression rather than TA, because hTERT is usually considered to reflect TA (10). However, TA does not always correlate with hTERT in colon cancer (11), possibly because of the presence of hTERT in infiltrating lymphocytes in normal mucosa. vi) Patients with familial polyposis or familial predisposition for hereditary nonpolyposis colon cancer (HNPCC). When numerous publications on the same research population were recognized, or when research populations showed repetition, the most up to date or complete study was used in the analysis. Both the article search and article selection were performed by two researchers independently. Any differences between the two researchers were solved by an agreement consulting a third researcher.

\section{Data extraction}

Information carefully extracted from the selected article included the following projects: the first author, year of publication, sample size, and mean age of the patients. Other retrieved information included the TA assessment method, cutoff values for TA positivity, and telomerase expression relating to clinicopathological parameters, including tumor size, tumor site, histologic differentiation, T category, $\mathrm{N}$ category, $\mathrm{M}$ category, and Dukes' or TNM stage classification. The original authors were emailed if necessary to provide the required information. Two authors independently extracted data. Disagreements were settled by a third author through discussion.

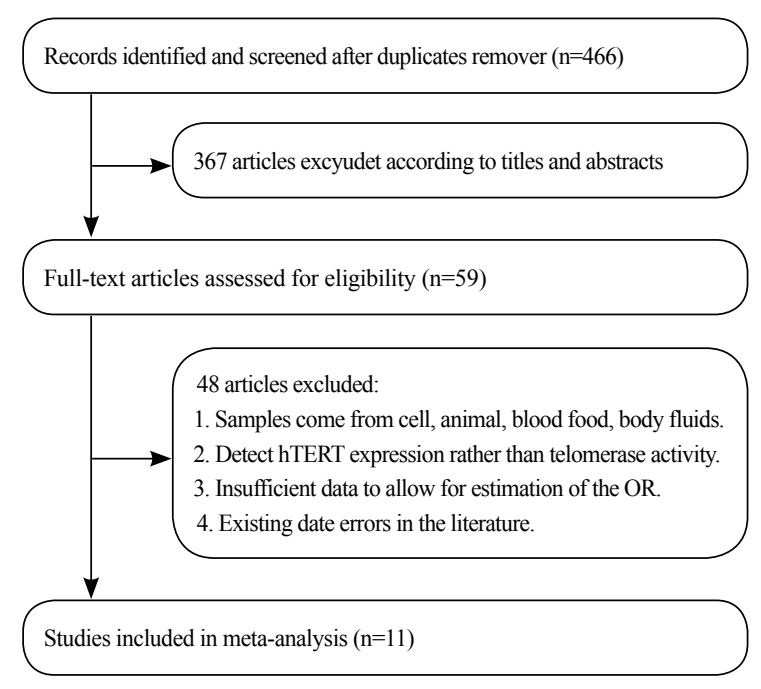

FIG. 1. Flow chart summarizing the literature search and study selection 
TABLE 1. Main characteristics of the 11 studies included in the meta-analysis.

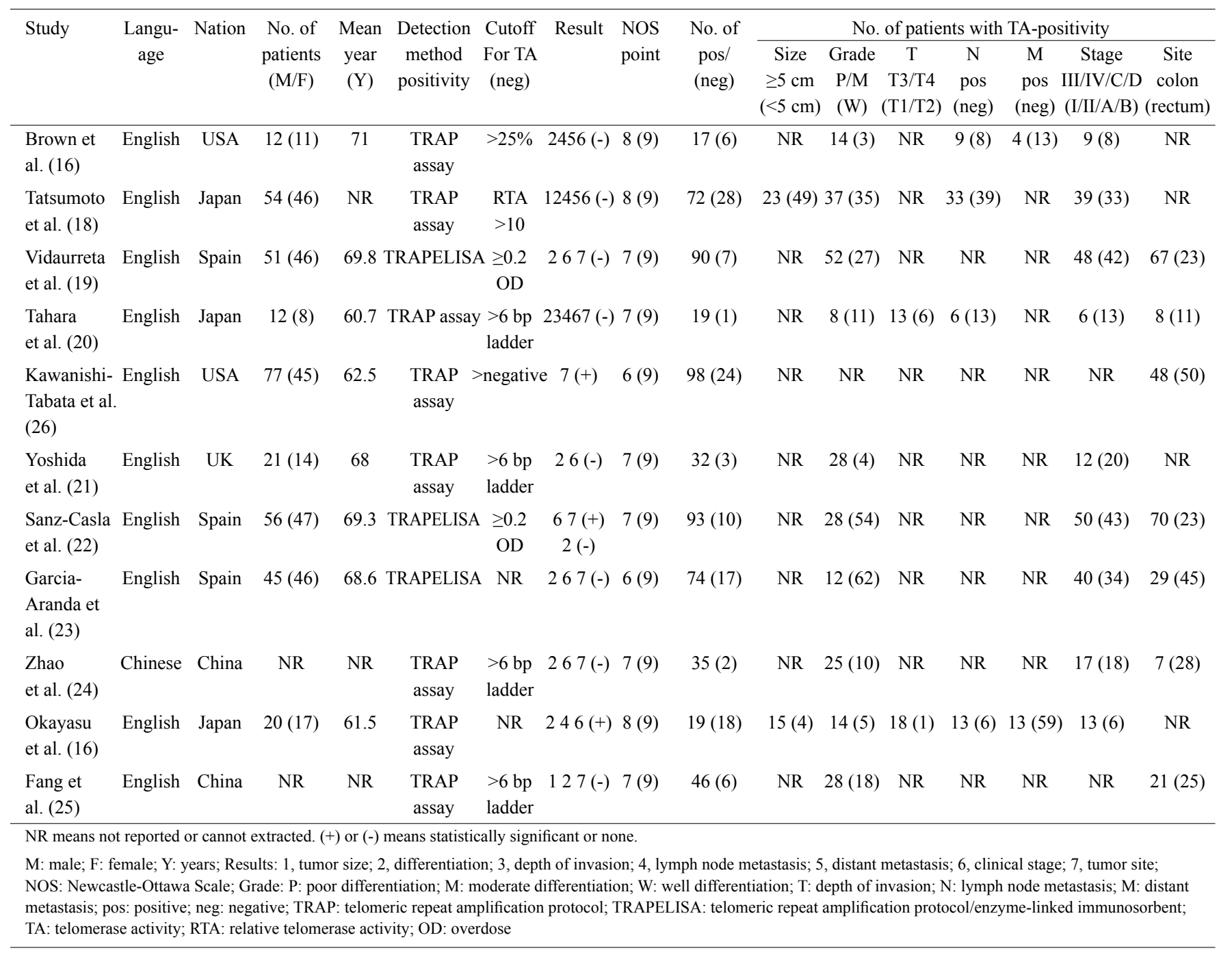

TABLE 2. Meta-analysis results according to clinicopathological parameters

\begin{tabular}{|c|c|c|c|c|c|c|c|c|c|c|}
\hline \multirow{2}{*}{$\begin{array}{l}\text { Clinicopathological } \\
\text { parameters }\end{array}$} & \multirow{2}{*}{$\begin{array}{l}\text { No. of } \\
\text { Studies }\end{array}$} & \multirow{2}{*}{$\begin{array}{l}\text { Analysis } \\
\text { model }\end{array}$} & \multicolumn{4}{|c|}{ Pooled Data } & \multicolumn{2}{|c|}{ Test for Heterogeneity } & \multicolumn{2}{|c|}{ Publication Bias } \\
\hline & & & Cases & OR & $95 \% \mathrm{CI}$ & $\mathrm{p}$ & $\mathrm{p}$ & $\mathrm{I} 2(\%)$ & Begg's & Egger's \\
\hline Tumor size $(\geq 5 \mathrm{~cm}$ vs. $<5 \mathrm{~cm})$ & 2 & Fixed-effects & 137 & 1.57 & $0.71-3.47$ & 0.267 & 0.288 & $11.4 \%$ & $\mathrm{NN}$ & $\mathrm{NN}$ \\
\hline Differentiation (P/M vs. W) & 10 & Fixed-effects & 570 & 1.28 & $0.78-2.09$ & 0.332 & 0.511 & $0 \%$ & 0.152 & 0.146 \\
\hline Tumor site (colon vs. rectum) & 7 & Fixed-effects & 522 & 2.93 & $1.29-6.67$ & 0.010 & 0.423 & $0 \%$ & 0.764 & 0.983 \\
\hline $\mathrm{T}(\mathrm{T} 3 / \mathrm{T} 4$ vs. T1/T2) & 2 & Fixed-effects & 57 & 3.76 & $0.61-23.04$ & 0.152 & 0.569 & $0 \%$ & $\mathrm{NN}$ & $\mathrm{NN}$ \\
\hline N (N1 vs. N0) & 4 & Fixed-effects & 180 & 2.85 & $1.40-5.81$ & 0.004 & 0.413 & $0 \%$ & $\mathrm{NN}$ & $\mathrm{NN}$ \\
\hline M (M1 vs. M0) & 2 & Fixed-effects & 123 & 1.76 & $0.54-5.74$ & 0.346 & 0.236 & $28.6 \%$ & $\mathrm{NN}$ & $\mathrm{NN}$ \\
\hline Clinical stage $(\mathrm{C}+\mathrm{D}$ vs. $\mathrm{A}+\mathrm{B})$ & 9 & Random effects & 543 & 1.59 & $0.74-3.38$ & 0.232 & 0.069 & $44.9 \%$ & 0.118 & 0.178 \\
\hline
\end{tabular}

No: number; NN: no need; N1: lymph node metastasis positive; N0: lymph node metastasis negative; M1: distant metastasis positive; M0: distant metastasis negative; OR: odds ratio; CI: confidence interval

\section{Qualitative assessment}

The quality of selected studies was evaluated alone by two authors on the basis of a 9-point scoring system, the Newcastle-Ottawa Scale (NOS) (12). This scale contains three broad perspectives: the selection (four items, one score each), comparability (one item, up to two scores), and outcome of interest for cohort studies (three items, one score each). 


\section{Statistical methods}

Telomerase activity was identified as having "positive" or "negative" expression according to the cut-off values supplied in each original article. For dichotomous variable outcomes, the analysis was carried out by using a crude OR with a $95 \%$ confidence interval (CI) to determine the strength of the relationship between TA and the CRC clinicopathological parameters. In some analyses, data were combined, including $\mathrm{T} 3$ and $\mathrm{T} 4$ versus $\mathrm{T} 1$ and $\mathrm{T} 2$, TNM stage III and IV (equivalent to Dukes' C and D) versus TNM stage I and II (equivalent to Dukes' A and B), and moderate and poor differentiation versus good differentiation. Assessment of heterogeneity was evaluated by the Chi-square test $\left(\chi^{2}\right.$; where $\mathrm{p}<0.10$ was considered heterogeneous) and the inconsistency index test (I; larger I values indicate higher heterogeneity). The randomeffects model was selected to solve any significant heterogeneity among the studies. Otherwise, the fixed-effects model (Mantel-Haenszel) was used (13). Using Begg's rank correlation test (14) and the Egger regression asymmetry test (15) to evaluate publication bias, a $p$ value of $>0.05$ was considered indicative of a lack of publication bias. Statistical analyses were performed using STATA version 12.0 (StataCorp, Texas, USA) and $<0.05$ was considered as significant.

\section{RESULTS}

\section{Study features}

Initially, a total of 466 publications were retrieved because of potentially relevant. Ultimately, 11 studies met the predefined inclusion criteria consisting of 715 patients for the final analyses (16-26). These eligible studies were published between 1995 and 2007. Sample sizes varied from 20 to 120 participants, and the average age from all of the studies was 66.4 years. The 11 eligible studies included eight retrospective cohort studies and three prospective cohort studies. TA expression levels were all measured in tumor tissue in these studies. All TA detection methods were telomeric repeat amplification protocol assays (TRAP) or telomeric repeat amplification protocol/enzyme-linked immunosorbent assays (TRAPELISA). The point of the NOS ranged from 6 to 8 (with a mean star rating of 7.1), with a higher value indicating a better methodology. The process of study search, inclusion, and exclusion is summarized in Figure 1. The main characteristics of the 11 studies are listed in Table 1 and 2.

\section{Meta-analysis results}

The meta-analysis results of the relationships between TA and clinicopathological parameters are provided in Figure 2. Among the results from our meta-analysis, there was no het- a

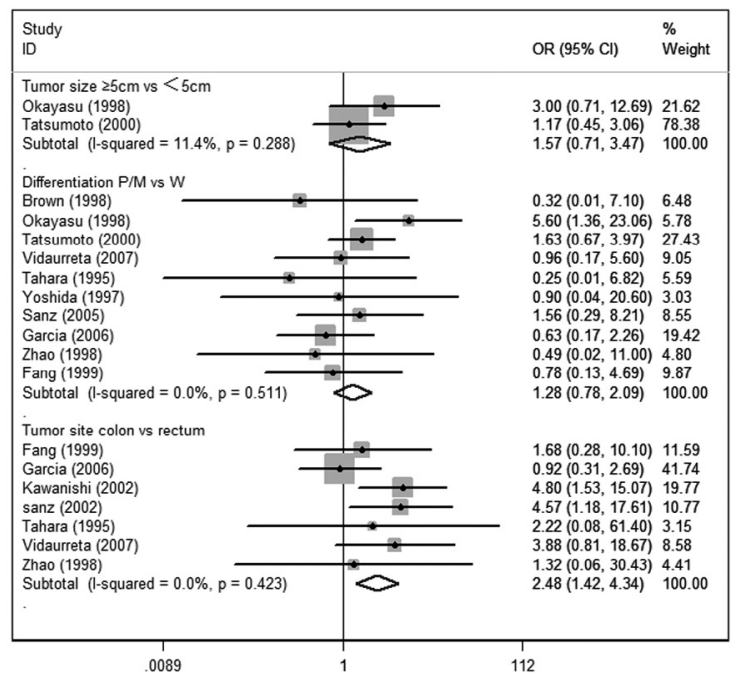

b

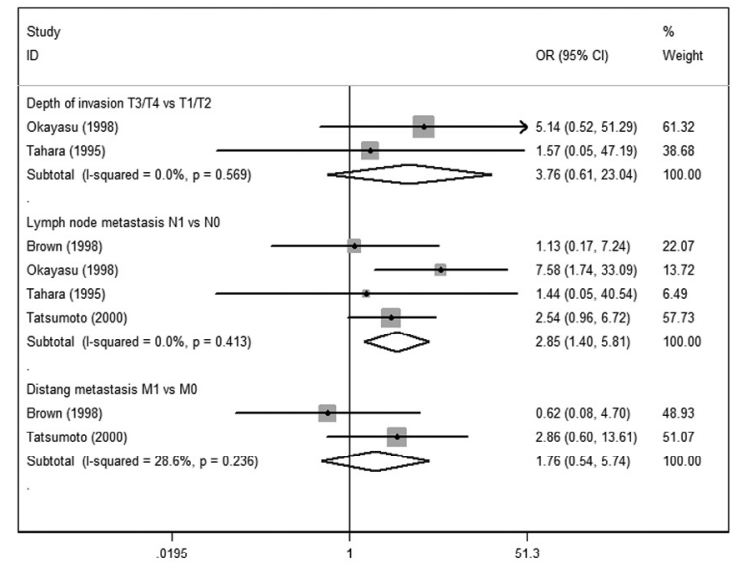

C

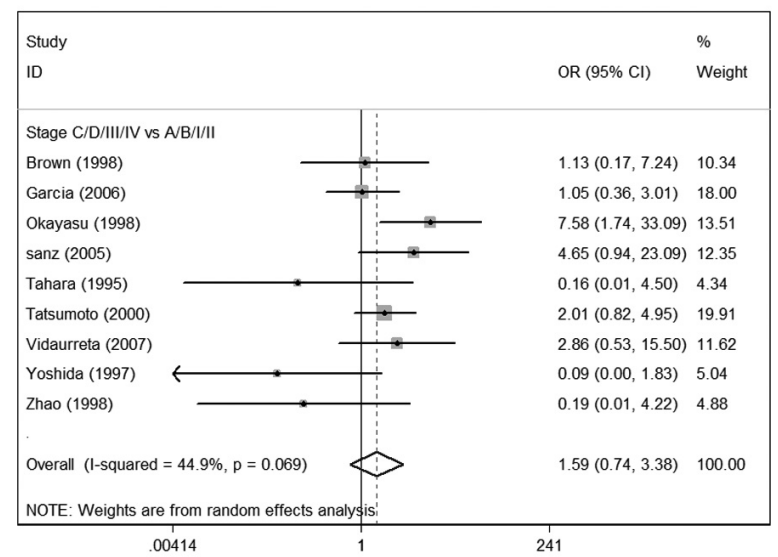

FIG. 2. a-c. Forest plots of TA and tumor size, differentiation and tumor site, respectively (a). Forest plots of TA and depth of tumor invasion, Lymph node metastasis, distant metastasis, respectively (b). Forest plots of TA and clinical stage (c).

erogeneity ( $p>0.1$ and $\mathrm{I}^{2}<30 \%$ ), other than when stratifying for Dukes' stage $\left(\mathrm{I}^{2}=44.9 \%, \mathrm{p}=0.069\right)$; thus, a randomeffects model was used for the latter and a fixed-effects model (Mantel-Haenszel) was used for the others. When the data were 

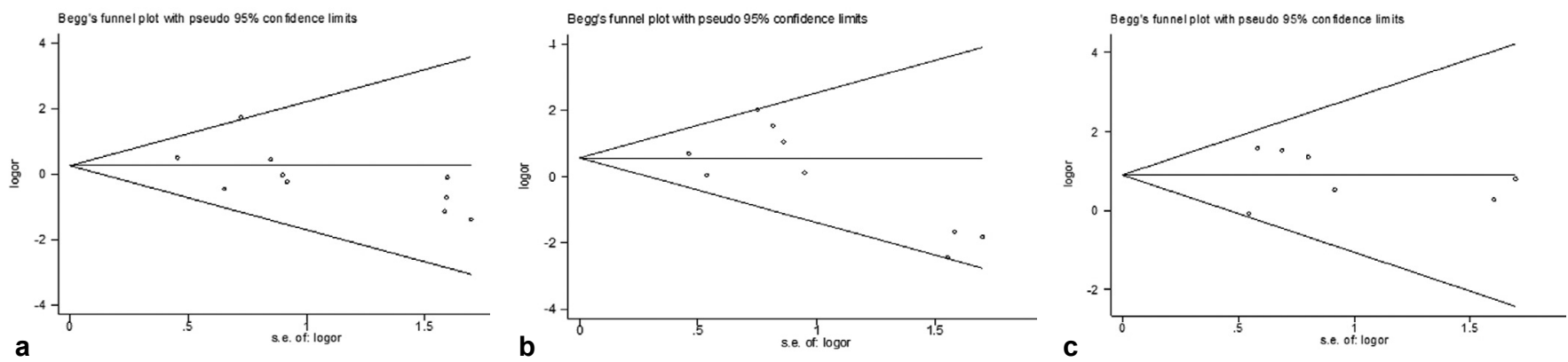

FIG. 3. a-c. Begg's funnel plots for the evaluation of potential publication bias on differentiation (a), clinical stage (b) and tumor site (c). LogOR, natural logarithm of OR; OR, odds ratio; seLogOR, standard error of LogOR

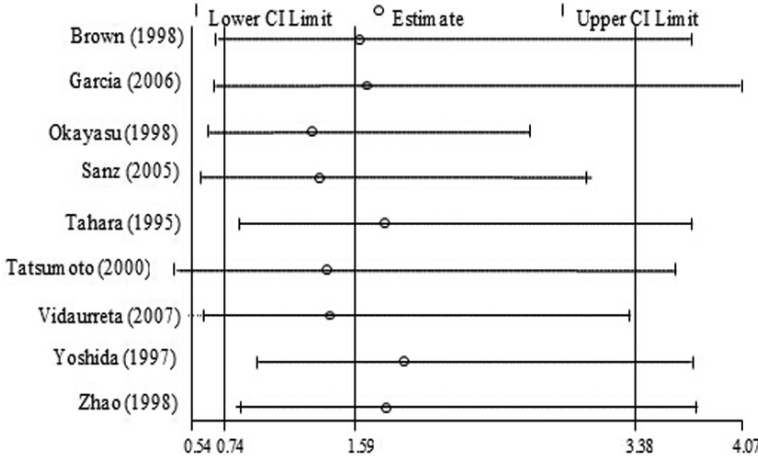

FIG. 4. Sensitivity analysis based on stepwise omitting one study at a time for clinic stage

pooled, there were significant associations between positive TA expression and both the tumor site and lymph node metastasis. Specifically, the pooled ORs, $95 \%$ CIs, and $\mathrm{p}$ values were as follows: $(\mathrm{OR}=2.48,95 \% \mathrm{CI}=1.42-4.34, \mathrm{p}=0.267)$ for tumor site (colon vs. rectum) and $(\mathrm{OR}=2.85,95 \% \mathrm{CI}=1.40$ $5.81, \mathrm{p}=0.004)$ for lymph node metastasis (N1 vs. N0). However, the data showed no significant associations between high TA expression and the tumor size of CRC patients (size $\geq 5$ cm vs. $<5 \mathrm{~cm}: \mathrm{OR}=1.57,95 \% \mathrm{CI}=0.71-3.47, \mathrm{p}=0.267)$, differentiation (poorly and moderately vs. well: $\mathrm{OR}=1.28,95 \%$ $\mathrm{CI}=0.78-2.09, \mathrm{p}=0.332)$, depth of invasion (T3/T4 vs. T1/ $\mathrm{T} 2$ : $\mathrm{OR}=3.76,95 \% \mathrm{CI}=0.61-23.04, \mathrm{p}=0.152$ ), distant metastasis (M1 vs. $\mathrm{M} 0$ : $\mathrm{OR}=1.76,95 \% \mathrm{CI}=0.54-5.74, \mathrm{p}=0.346$ ), and clinical stage $(\mathrm{C} / \mathrm{D} / \mathrm{II} / \mathrm{IV}$ vs. $\mathrm{A} / \mathrm{B} / \mathrm{I} / \mathrm{II}: \mathrm{OR}=1.59,95 \%$ $\mathrm{CI}=0.74-3.38, \mathrm{p}=0.232)$.

\section{Publication bias}

Begg's funnel plot and Egger's test were performed to assess the publication bias of the eligible studies on the differentiation, clinical stage, and tumor site. As shown in Figure 3 , the shape of the funnel plot did not reveal any evidence of visible asymmetry. The Begg's test and Egger's test was then adopted to afford statistical evidence of funnel plot symmetry.
Ultimately, this meta-analysis observed no significant publication biases $(\mathrm{p}=0.152, \mathrm{p}=0.118$, and $\mathrm{p}=0.764$ for Begg's test; $p=0.146, p=0.178$, and $p=0.983$ for Egger's test, respectively).

\section{Sensitivity analyses}

There was a slight statistical heterogeneity in the analysis of the association between TA and clinical stage $\left(\mathrm{I}^{2}=44.9 \%, \mathrm{p}\right.$ $0.069)$. Sensitivity analyses were performed to find possible sources of statistical heterogeneity. The outcomes showed there was no significant variation in combined hazard ratio (HR) by excluding any of the studies, suggesting that the estimates were robust (Figure 4).

\section{DISCUSSION}

The prognosis of patients with colorectal cancer is correlated with the depth of the primary tumor invasion (Dukes' classification), lymph node metastasis, and pathological findings $(27,28)$. However, these factors are not sufficient to predict the overall survival of patients with colorectal cancer. In recent years, many molecular markers, such as adenomatous polyposis coli (APC) and TP53 (tumor protein 53) (29), which function as tumor suppressor genes, and KRAS/BRAF (30), which function as oncogenes, have been investigated to improve clinical therapy for patients with CRC. Although many efforts have been made, no agreement has been reached regarding the clinical usefulness of these markers. Therefore, it is critical for researchers to identify a novel predictive and prognostic marker.

For a few decades, a variety of studies have investigated the enzymatic activity of telomerase in colorectal cancer. However, whether the activity of telomerase is associated with clinicopathological features of patients remains controversial. Some articles have shown that the TA in CRC tissue is related to the depth of differentiation (17), tumor invasion (26), lymph node metastasis (17), and stage $(17,22,31)$. Neverthe- 
less, other researches have not yet found an association between TA and clinical outcomes (16, 18-20, 23). However, it is also noteworthy that TA expression in the colon or rectum is debatable $(22,23,25,26)$.

In light of these previous findings, we performed a metaanalysis of the evidence taken from entire published articles for the purpose of providing a quantitative revaluation of the connection. In our analysis, TA was detected from all colorectal cancer tissues. Studies measured TA by using TRAP assays or TRAPELISA assays. We ultimately observed a significant association between a positive TA and several clinicopathological parameters including: lymph node metastasis $(\mathrm{OR}=2.85$, $95 \% \mathrm{CI}=1.40-5.81, \mathrm{p}=0.004)$ and tumor site $(\mathrm{OR}=2.93,95 \%$ $\mathrm{CI}=1.29-6.67, \mathrm{p}=0.010$ ). Pooled data also suggested an evident tend towards higher TA with factors such as larger tumor size, poor differentiation, the depth of invasion, distant metastases, and advanced Dukes' or TNM stage; however, the statistical significance of these relationships did not reach the significance level $(\mathrm{p}>0.5)$.

It is worth noting that our results have some differences from a similar meta-analysis that examined TA and clinicopathological parameters in gastric cancer (32). Results from this previous study indicated that high TA expression tended to be associated with lymph node metastasis, the depth of invasion, distant metastasis, tumor size, and TNM stage. The possible reasons for this disparity might be because the analysis strategy used in the previous article included both telomerase and hTERT in gastric cancer, and its analysis sample size was larger with greater heterogeneity. In CRC, while hTERT is the rate-limiting step in the activation of telomerase (10), TA does not always correlate with hTERT. This is possibly because of the presence of hTERT in infiltrating lymphocytes in normal mucosa (11). Interestingly, both outcomes showed that high TA expression tended to be linked with the existence of lymph node metastasis.

Lymph node metastasis signals an invasive cancer behavior and is related to a high rate of local recurrence, which indicates a poor prognosis and perhaps induce signally morbidity $(33,34)$. Consequently, it would be clinically advantageous to identify and diagnose lymph node metastasis early in cause of improving treatment to produce a better outcome for tumor patients. Patients with TNM stage III disease require adjuvant therapy after surgical resection, but whether adjuvant therapy should be given to patients with TNM stage II disease is still controversial $(35,36)$. In analyzing our results, we suggest that those positive TA patients with TNM stage II CRC are highly likely to have undetectable micrometastases. Thus, a positive TA may be a better classifier in identifying the subpopulation of TNM stage II patients who could benefit from therapy.
Our results showed statistical significance only in the correlation between lymph node metastasis and TA. However, as mentioned previously, while $50 \%$ in stage III CRC with lymph node metastasis after a surgical resection is performed, the rate is approximately $85 \%$ in CRC patients without lymph node metastasis in the early stages (2). Thus, TA may be a viable marker in predicting the progression and prognosis of CRC patients. Certainly, the molecular mechanisms of TA promotion of tumor progression need more comprehensive understanding. For instance, telomerase can affect the tumor proliferation rate to induce tumor progression (37). Bagheri et al. (38) found that TA regulates the glycolytic pathway, which could increase the energy supply status of tumor cells, thereby promoting tumor invasion and metastasis. Studies have also found that telomerase can induce cell expression of epidermal growth factor (EGFR) (39) or transforming growth factor- $\beta$ (TGF- $\beta$ ) (40) to stimulate cell proliferation. In fact, prognostic values of TA for overall survival in CRC patients are significantly correlated, those who had telomerase activated without 3'OH shortened telomeres had a poor prognosis (41). Patients with telomerase negative tumors had better overall survival than patients with telomerase positive tumors (19). In addition, TA was able to predict a greater risk of death and recurrence, independent of conventional prognostic factors (e.g., Dukes' stage and tumor site) (22). Currently, there is a general agreement that TA is strongly linked with tumor development and may play a critical role as a biomarker for cancer prognosis $(42,43)$.

In the current study, the connection between TA positive and other clinicopathological parameters (e.g., distant metastasis and clinical stage) was not statistically significant. This suggests that normal epithelial cells may be susceptible to telomerase drive to form new tumors. However, in advanced colon cancer systemic disease, this effect may either be reduced or the normal colonic epithelial cells may not have such strong regenerative powers. These theories offer a possible interpretation. Furthermore, the present metaanalysis also indicated that colon and rectal cancers seem to have different levels of TA-colon cancer had a significantly positive level compared to rectal cancer. These results are also consistent with the latest research (44). This variation in TA levels could be another factor responsible for the different progressions and biological and clinical behaviors. These results support the idea that the large bowel cannot be considered a uniform organ, at least in terms of cancer biology.

To the best of our knowledge, this meta-analysis is the first systematic review evaluating the relationship between TA and clinicopathological parameters in CRC; we believe that this report offers several strengths. First, we used a rigorous search strategy, we avoided a language limitation, we used a stringent 
inclusion criteria, and we used a careful approach to selecting a fixed- or random-effects model for pooling studies according to whether they had significant heterogeneity. The publication bias and sensitivity analysis were then performed to evaluate the effect of losing studies and to analyze sources of heterogeneity. Despite the strengths of our study, caution must be taken in light of the limitations. First, patients only came from Asia and Europe, which may result in a population bias. Second, as in similar studies, our analysis also had to admit that a potential source of bias may arise from the differently defined cutoff values of a positive expression amongst studies. Third, the sample size was relatively small due to the strict inclusion criteria and this may not provide sufficient statistical power to estimate the relationship between TA and various clinical features. Fourth, although TA was related to some clinical features, it is not clear whether TA is a prognostic factor, as determined by multivariate analysis. Thus, further studies are required to confirm the full prognosis role of TA in CRC.

In conclusion, this meta-analysis suggests that a positive TA was correlated with lymph node metastasis progression and tumor sites of CRC. TA can play a useful part in the prognosis and the treatment of CRC patients, but further studies are required to confirm this.

\section{Ethics Committee Approval: N/A.}

\section{Informed Consent: N/A.}

Peer-review: Externally peer-reviewed.

Author contributions: Concept - X.C.X.; Design - X.C.X., Y.Z.Q.; Supervision - X.C.X., Y.Z.Q.; Resource - L.Y.G.; Materials - L.Y.G.; Data Collection \&/or Processing - F.T.; Analysis \&/or Interpretation - X.C.X., Y.Z.Q.; Literature Search - X.C.X., H.L., H.Q.; Writing - X.C.X., Y.Z.Q.; Critical Reviews - X.C.X., L.Y.G., H.L., H.Q., F.T., Y.Z.Q.

Conflict of Interest: No conflict of interest was declared by the authors.

Financial Disclosure: The authors declared that this study has received no financial support.

\section{REFERENCES}

1. Siegel R, Naishadham D, Jemal A. Cancer statistics, 2013. CA Cancer J Clin 2013;63:11-30. [CrossRef]

2. O'Connell JB, Maggard MA, Ko CY. Colon cancer survival rates with the new American Joint Committee on Cancer sixth edition staging. J N Cancer Inst 2004;96:1420-5. [CrossRef]

3. Hegde MV, Mali AV, Chandorkar SS. What is a cancer cell? Why does it metastasize? Asian Pac J Cancer Prev 2013;14:3987-9. [CrossRef]
4. Podlevsky JD, Chen JJ. It all comes together at the ends: telomerase structure, function, and biogenesis. Mutat Res 2012;730:311. [CrossRef]

5. Feng J, Funk WD, Wang SS, Weinrich SL, Avilion AA, Chiu $\mathrm{CP}$, et al. The RNA component of human telomerase. Science 1995;269:1236-41. [CrossRef]

6. Cukusic A, Skrobot Vidacek N, Sopta M, Rubelj I. Telomerase regulation at the crossroads of cell fate. Cytogenet Genome Res 2008;122:263-72. [CrossRef]

7. Chen $\mathrm{CH}$, Chen RJ. Prevalence of telomerase activity in human cancer. J Formos Med Assoc 2011;110:275-89. [CrossRef]

8. Valls Bautista C, Pinol Felis C, Rene Espinet JM, Buenestado Garcia J, Vinas Salas J. Telomerase activity and telomere length in the colorectal polyp-carcinoma sequence. Rev Esp Enferm Dig 2009;101:179-86. [CrossRef]

9. Stroup DF, Berlin JA, Morton SC, Olkin I, Williamson GD, Rennie D, et al. Meta-analysis of observational studies in epidemiology: a proposal for reporting. Meta-analysis Of Observational Studies in Epidemiology (MOOSE) group. JAMA 2000;283:2008-12. [CrossRef]

10. Poole JC, Andrews LG, Tollefsbol TO. Activity, function, and gene regulation of the catalytic subunit of telomerase (hTERT). Gene 2001;269:1-12. [CrossRef]

11. Tahara H, Yasui W, Tahara E, Fujimoto J, Ito K, Tamai K, et al. Immuno-histochemical detection of human telomerase catalytic component, hTERT, in human colorectal tumor and non-tumor tissue sections. Oncogene 1999;18:1561-7. [CrossRef]

12. Wells GA, Shea B, O'Connell D, Peterson J, Welch V, Losos M, et al. The Newcastle-Ottawa Scale (NOS) for assessing the quality if nonrandomized studies in meta-analyses.

13. Higgins JP, Thompson SG, Deeks JJ, Altman DG. Measuring inconsistency in meta-analyses. BMJ (Clinical research ed) 2003;327:557-60. [CrossRef]

14. Begg CB, Mazumdar M. Operating characteristics of a rank correlation test for publication bias. Biometrics 1994;50:1088-101. [CrossRef]

15. Egger M, Davey Smith G, Schneider M, Minder C. Bias in metaanalysis detected by a simple, graphical test. BMJ 1997;315:62934. [CrossRef]

16. Brown T, Aldous W, Lance R, Blaser J, Baker T, Williard W. The association between telomerase, p53, and clinical staging in colorectal cancer. Am J Surg 1998;175:364-6. [CrossRef]

17. Okayasu I, Mitomi H, Yamashita K, Mikami T, Fujiwara M, Kato $\mathrm{M}$, et al. Telomerase activity significantly correlates with cell differentiation, proliferation and lymph node metastasis in colorectal carcinomas. J Cancer Res Clin Oncol 1998;124:4449. [CrossRef]

18. Tatsumoto N, Hiyama E, Murakami Y, Imamura Y, Shay JW, Matsuura Y, et al. High telomerase activity is an independent prognostic indicator of poor outcome in colorectal cancer. Clin Cancer Res 2000;6:2696-701.

19. Vidaurreta M, Maestro ML, Rafael S, Veganzones S, SanzCasla MT, Cerdan J, et al. Telomerase activity in colorectal cancer, prognostic factor and implications in the microsatellite 
instability pathway. World J Gastroenterol 2007;13:3868-72. [CrossRef]

20. Tahara H, Kuniyasu H, Yokozaki H, Yasui W, Shay JW, Ide T, et al. Telomerase activity in preneoplastic and neoplastic gastric and colorectal lesions. Clin Cancer Res 1995;1:1245-51.

21. Yoshida K, Sugino T, Goodison S, Warren BF, Nolan D, Wadsworth S, et al. Detection of telomerase activity in exfoliated cancer cells in colonic luminal washings and its related clinical implications. Br J Cancer 1997;75:548-53. [CrossRef]

22. Sanz-Casla MT, Vidaurreta M, Sanchez-Rueda D, Maestro ML, Arroyo M, Cerdan FJ. Telomerase activity as a prognostic factor in colorectal cancer. Onkologie 2005;28:553-7. [CrossRef]

23. Garcia-Aranda C, de Juan C, Diaz-Lopez A, Sanchez-Pernaute A, Torres AJ, Diaz-Rubio E, et al. Correlations of telomere length, telomerase activity, and telomeric-repeat binding factor 1 expression in colorectal carcinoma. Cancer 2006;106:541-51. [CrossRef]

24. Zhao D, Zhang W, Jin S. Study of telomerase activity in colorectal carcinomas. Zhonghua Zhong Liu Za Zhi 1998;20:199-201.

25. Fang DC, Young J, Luo YH, Lu R, Jass J. Detection of telomerase activity in biopsy samples of colorectal cancer. J Gastroenterol Hepatol 1999;14:328-32. [CrossRef]

26. Kawanishi-Tabata R, Lopez F, Fratantonio S, Kim N, Goldblum $\mathrm{J}$, Tubbs R, et al. Telomerase activity in stage II colorectal carcinoma. Cancer 2002;95:1834-9. [CrossRef]

27. Dukes CE. The classification of cancer of the rectum. $J$ Pathol Bacteriol 1932;35:323-32. [CrossRef]

28. Jass JR, Love SB, Northover JM. A new prognostic classification of rectal cancer. Lancet 1987;1:1303-6. [CrossRef]

29. Westra JL, Schaapveld M, Hollema H, de Boer JP, Kraak MM, de Jong D, et al. Determination of TP53 mutation is more relevant than microsatellite instability status for the prediction of disease-free survival in adjuvant-treated stage III colon cancer patients. J Clin Oncol 2005;23:5635-43. [CrossRef]

30. Roth AD, Tejpar S, Delorenzi M, Yan P, Fiocca R, Klingbiel D, et al. Prognostic role of KRAS and BRAF in stage II and III resected colon cancer: results of the translational study on the PETACC-3, EORTC 40993, SAKK 60-00 trial. J Clin Oncol 2010;28:466-74. [CrossRef]

31. Ghori A, Usselmann B, Ferryman S, Morris A, Fraser I. Telomerase expression of malignant epithelial cells correlates with Dukes' stage in colorectal cancer. Colorectal Dis 2002;4:441-6. [CrossRef]
32. Lü MH, Deng JQ, Cao YL, Fang DC, Zhang Y, Yang SM. Prognostic role of telomerase activity in gastric adenocarcinoma: A meta-analysis. Exp Ther Med 2012;3:728-34.

33. Chang GJ, Rodriguez-Bigas MA, Skibber JM, Moyer VA. Lymph node evaluation and survival after curative resection of colon cancer: systematic review. J Natl Cancer Inst 2007;99:433-41. [CrossRef]

34. Maehara Y, Oshiro T, Endo K, Baba H, Oda S, Ichiyoshi Y, et al. Clinical significance of occult micrometastasis lymph nodes from patients with early gastric cancer who died of recurrence. Surgery 1996;119:397-402. [CrossRef]

35. Chua YJ, Zalcberg JR. Progress and challenges in the adjuvant treatment of stage II and III colon cancers. Expert Revanticancer Ther 2008;8:595-604. [CrossRef]

36. Wolpin BM, Mayer RJ. Systemic treatment of colorectal cancer. Gastroenterology 2008;134:1296-310. [CrossRef]

37. Jin X, Beck S, Sohn YW, Kim JK, Kim SH, Yin J, et al. Human telomerase catalytic subunit (hTERT) suppresses p53-mediated anti-apoptotic response via induction of basic fibroblast growth factor. Exp Mol Med 2010;42:574-82. [CrossRef]

38. Bagheri S, Nosrati M, Li S, Fong S, Torabian S, Rangel J, et al. Genes and pathways downstream of telomerase in melanoma metastasis. Proc Natl Acad Sci USA 2006;103:11306-11. [CrossRef]

39. Geserick C, Tejera A, Gonzalez-Suarez E, Klatt P, Blasco MA. Expression of mTert in primary murine cells links the growthpromoting effects of telomerase to transforming growth factorbeta signaling. Oncogene 2006;25:4310-9. [CrossRef]

40. Smith LL, Coller HA, Roberts JM. Telomerase modulates expression of growth-controlling genes and enhances cell proliferation. Nat Cell Biol 2003;5:474-9. [CrossRef]

41. Kojima K, Hiyama E, Otani K, Ohtaki M, Fukuba I, Fukuda $\mathrm{E}$, et al. Telomerase activation without shortening of telomeric 3 '-overhang is a poor prognostic factor in human colorectal cancer. Cancer Sci 2011;102:330-5. [CrossRef]

42. Saleh S, Lam AK, Ho YH. Real-time PCR quantification of human telomerase reverse transcriptase (hTERT) in colorectal cancer. Pathology 2008;40:25-30. [CrossRef]

43. Bertorelle R, Briarava M, Rampazzo E, Biasini L, Agostini M, Maretto I, et al. Telomerase is an independent prognostic marker of overall survival in patients with colorectal cancer. Br J Cancer 2013;108:278-84. [CrossRef]

44. Ayiomamitis GD, Notas G, Zaravinos A, Zizi-Sermpetzoglou A, Georgiadou M, Sfakianaki O, et al. Differences in telomerase activity between colon and rectal cancer. Can J Surg 2014;57:199-208. [CrossRef] 